spanish

\title{
La formación de mercados de alimentos en Argentina: un análisis sobre la comercialización de las harinas de trigo entre Santa Fe y las plazas norteñas (1880-1895)
}

\section{The Evolution of Food Markets in Argentina: An Analysis on the Commercialization of Flour between Santa Fe and the Northern Markets (1880-1895)}

Juan L. Martirén 1,2, * iD 0000-0002-0826-2879

Daniel Moyano ${ }^{2,3}$ (iD 0000-0003-2269-6750

\footnotetext{
${ }^{1}$ Universidad de Buenos Aires, Instituto de Historia Argentina y Americana Dr. Emilio Ravignani, Buenos Aires, Argentina.

${ }^{2}$ Consejo Nacional de Investigaciones Científicas y Técnicas, Buenos Aires, Argentina.

${ }^{3}$ Universidad Nacional de Tucumán, Instituto Superior de Estudios Sociales, Tucumán, Argentina.

*Correspondencia: jlmartiren@hotmail.com
}

Resumen. Se analiza el desarrollo de los canales de comercialización de las harinas de trigo, con el fin de aportar nueva evidencia que permita explicar la conformación de mercados integrados de bienes de consumo en la Argentina de fines del siglo xIx. Los intermediarios desempeñaron un papel central en el dominio alcanzado por las harinas de Santa Fe en las plazas del norte -particularmente Tucumán- desde la década de 1880, desplazando a abastecedores tradicionales. A partir de un análisis del vínculo comercial

CÓMO CITAR: MARTIRéN, J. L. y MOYANO, D. (2019). La formación de mercados de alimentos en Argentina: un análisis sobre la comercialización de las harinas de trigo entre Santa Fe y las plazas norteñas (1880-1895). América Latina en la Historia Económica, 26(1), e935. DOI: 10.18232/ALHE.935 
entre ambas plazas se busca mostrar la dinámica de funcionamiento de los intermediarios, sus conexiones, sus efectos sobre la conformación de los precios y sus estrategias de diferenciación de productos y captación de clientes.

Palabras clave: comercialización; mercados; marcas; intermediación.

Abstract. This paper studies the development of flour supply chains between Santa Fe and the Northern markets in Argentina. It aims to provide new evidence to explain the emergence of integrated domestic consumer good markets in the country during the late $19^{\text {th }}$ century. Based on archives from two privately owned Santa Fe wheat mills and trade information published in Tucuman's newspapers, we analyze the commercial links between both markets by showing the functioning dynamics of the intermediaries, their connections, the effects on prices and the product differentiation and customer strategies. We argue that intermediaries played a central role in the dominance of the Santa Fe flour producers in the Northern markets.

Key words: commercialization; markets; branding; intermediaries.

JEL: N36; N76; N96; R1.

Recibido: 21 de noviembre de 2017.

Aceptado: 28 de febrero de 2018.

Publicado: 20 de junio de 2018

\section{INTRODUCCIÓN}

El crecimiento económico experimentado por Argentina durante el último cuarto del siglo XIX generó importantes transformaciones en su estructura productiva y comercial. Dicha expansión estuvo motivada por un aumento exponencial de la producción agropecuaria acompañada por el desarrollo de industrias generadoras de valor agregado a partir de diversas materias primas. Como consecuencia, se promovió un considerable parque de infraestructuras en el que se destacaron los ferrocarriles y telégrafos, que conectaron los principales centros productivos con las grandes plazas de abasto y consumo, y la modernización de los puertos de exportación de bienes primarios de origen agrario (Hora, 2010; Zalduendo, 1975).

Entre las actividades transformadoras de este tipo de productos en alimentos y bienes de consumo no durables sobresalieron, durante el periodo estudiado, las agroindustrias del azúcar de caña, la vitivinicultura, la molienda de trigo, y la industria frigorífica en su fase inicial. Estas actividades tuvieron un notable desarrollo manifiesto en sus escalas de inversión, capacidad instalada y tecnología incorporada 11 La industria azucarera se desarrolló en los valles fértiles del cuadrante noroeste del actual territorio argentino, con epicentro en la provincia de Tucumán (Campi y Bravo, 1999; Guy, 1981). La molinera, por su parte, evidenció una sostenida expansión gracias al auge triguero experimentado, sobre todo, en las colonias del centro de la provincia de Santa Fe. Ya en menor escala se desarrollaron otras -ubicadas generalmente en las grandes ciudades- como la industria cervecera, la destilación de granos y demás actividades derivadas, como la fabricación de galletitas, fidelerías, licorerías, entre otras (Barsky y Gelman, 2001; Belini, 2017; Gallo 1983; Gallo y Cortés-Conde, 1972; Hora, 2010; Míguez, 2008; Rocchi, 2006).

\footnotetext{
${ }^{1}$ Información estadística agregada sobre el crecimiento relativo que tuvieron estas industrias en censos nacionales de 1895 y 1914, véase República Argentina (1899 y 1917).
} 
La literatura económica muestra un considerable avance en diferentes aristas relacionadas con la génesis y consolidación de diversos núcleos productivos regionales, que explican el crecimiento económico argentino de fines del siglo XIx. Empero, aún persisten notorios vacíos historiográficos. Por ejemplo, la mayoría de las investigaciones ha echado mano sobre estadísticas agregadas que no permiten comprender cómo se produjo la llegada de sus productos a plazas de consumo, o bien establecer quiénes fueron los actores que permitieron transformar y/o dinamizar los circuitos mercantiles tradicionales ${ }^{2}$ Es decir, el foco de interés de los investigadores se ha centrado mayormente en la producción y ha dejado de lado otros factores clave, como la comercialización o el proceso de articulación de diferentes mercados regionales en la Argentina decimonónica ${ }^{3}$ Por lo tanto, no existen aún explicaciones integrales sobre los efectos que el crecimiento de estos sectores industriales tuvo sobre la esfera de la comercialización o bien sobre las estructuras económicas regionales. En pos de cubrir parte de estas lagunas, el presente trabajo se focalizará específicamente en el desarrollo de los canales de comercialización de las harinas de trigo, con el fin de aportar nueva evidencia que permita explicar parte del complejo proceso de formación de mercados integrados de bienes de consumo en la Argentina de fines del siglo XIx.

La elección de este sector industrial se justifica no sólo por su importancia relativa en el crecimiento del PBI industrial durante el periodo, sino por sus particularidades en el proceso de conformación y provisión de nuevos mercados o plazas de consumo en el interior del país. En efecto, los molinos localizados en la provincia de Santa Fe desempeñaron un papel central, en tanto fueron los principales promotores del cambio tecnológico en la producción de harinas y lograron polvos con altos estándares de calidad que permitieron copar importantes plazas de consumo anteriormente provistas por la oferta extranjera o bien por la producción local (Djenderedjian, Bearzotti y Martirén, 2010; Fernández, 1999; Gallo, 1983).

Los primeros excedentes logrados a fines de la década de 1870 comenzaron a utilizar los canales de comercialización abiertos por la creciente producción triguera local, orientados a Buenos Aires y, posteriormente, a Brasil. Sin embargo, para fines de esa década la producción de harinas santafesina también comenzaría a expandir sus horizontes hacia el interior del país, aprovechando el costo de oportunidad que generaban los canales de comercialización abiertos por la provincia de Tucumán como proveedor de azúcares a los mercados de la región pampeana, particularmente las ciudades portuarias como Rosario de Santa Fe y Buenos Aires. Este proceso, del que aún conocemos poco, presenta un caso interesante para entender mejor cómo afectó el crecimiento de las industrias procesadoras de alimentos durante el periodo analizado en economías anteriormente cubiertas por producciones locales o regionales. Si bien las estadísticas sobre comercialización de harinas en el norte argentino son escasas y bastante disgregadas, los pocos datos existentes dan cuenta de un importante crecimiento de los envíos de harinas desde el núcleo productor santafesino. Esto es notorio, además, en las fuentes cualitativas, en especial la información mercantil publicada en la prensa periódica, que evidencia una excluyente presencia de las harinas pampeanas en la oferta comercial y una virtual desaparición de los antiguos abastecedores y de los productores locales. Esto será desarrollado en líneas posteriores.

\footnotetext{
${ }^{2}$ Los trabajos que analizaron o se aproximaron a la comercialización de cereales han centrado su preocupación en las grandes casas de comercio, dejando prácticamente invisibilizada una extendida red de intermediarios de mediana y pequeña escala, fundamental en los mercados regionales. Véase Scobie (1968) y Adelman (1990).

${ }^{3}$ En los últimos años, este problema ha sido eje de algunos abordajes relevantes, aunque no directamente orientados al análisis de este ensayo. Véanse Lluch (2004, 2015), Frid (2006) y Rocchi (2016).
} 
En lo que respecta al soporte documental, apelaremos a fuentes privadas de molinos harineros y a informes oficiales, estadísticas y publicaciones periódicas provinciales para analizar las estructuras de comercialización y el proceso de integración de mercados entre dos ámbitos regionales: por un lado, la provincia de Santa Fe, consolidada como el principal núcleo productor de harinas en Argentina del periodo; y por otro, las plazas de consumo del norte argentino, especialmente Tucumán, principal epicentro azucarero del país, provincia con mayor población en la región y eje articulador del tendido ferroviario que unía al norte con las demás regiones del país. Las fuentes privadas provienen de la contabilidad y la correspondencia de dos molinos harineros de la provincia de Santa Fe, que funcionaron entre las décadas de 1880 e inicios del siglo xx. Dichos documentos proveen información diaria sobre precios de harinas, rendimientos, intercambios epistolares con acopiadores e intermediarios de distintas plazas del país, entre otras cuestiones. Cruzamos esta información con una exhaustiva recopilación de los partes comerciales y publicidades aparecidos en el diario tucumano El Orden. Todo esto nos permitió conformar listas de información nominal de los intermediarios y comerciantes, y confeccionar series de precios en distintos mercados basándonos en la contabilidad privada de los molinos y la prensa para la plaza oferente (Santa Fe) y en los boletines de precios en la plaza de consumo e intermediación hacia el norte (Tucumán).

El trabajo se compondrá de cuatro partes: en primer lugar, se hará un breve repaso sobre el proceso de industrialización de la molienda de trigo en la provincia de Santa Fe (y en particular en sus colonias agrícolas). Seguidamente, se examinará la conformación y las características de los canales de comercialización utilizados por los empresarios harineros en busca de nuevas plazas de consumo y los cambios que se fueron dando con la modernización de la infraestructura. En tercer lugar, se analizará el comportamiento de los precios durante el periodo estudiado mediante la presentación de series inéditas de cotizaciones del producto en dos plazas del interior (Santa Fe y Tucumán), a las que se adicionarán las ya conocidas para Buenos Aires. Este ejercicio comparativo adquiere importancia en la medida en que permitirá aportar nueva evidencia para estudiar el complejo proceso de integración de los mercados de bienes de consumo durante esta etapa. Por último, se abordará otro eje central de la comercialización: las estrategias de diferenciación de los productos mediante la emergencia de las marcas, rótulos o sellos distintivos en el mercado de alimentos. Con esto se pretende evidenciar cómo esta variable adquirió notoriedad en el momento en que la integración mercantil entre las grandes plazas comerciales del país era ya un hecho evidente.

\section{LA EMERGENCIA DE LA MODERNA INDUSTRIA HARINERA EN ARGENTINA}

Desde mediados del siglo xIx, las colonias agrícolas santafesinas cambiaron progresivamente el paisaje agrario pampeano y la oferta de factores al promover la agricultura extensiva en secano sobre tierras yermas o escasamente capitalizadas. Luego de dos décadas de experimentación, se logró consolidar una receta productiva basada en la incorporación de maquinaria moderna (arados dobles, segadoras mecánicas y trilladoras a vapor), que permitió ampliar radicalmente la tradicional escala productiva (Martirén, 2016). A la par de la maquinaria también se introdujeron importantes mejoras en la calidad de las semillas, manejo de los suelos, aprovechamiento de los barbechos, entre otras cuestiones, lo que muestra a las claras el notable crecimiento que tuvo el paquete tecnológico aplicado a las sementeras de trigo en las colonias santafesinas, y que le permitió incrementar las escalas de producción y lograr una mejora en la calidad de los granos (Djenderedjian, Bearzotti y 
Martirén, 2010). Santa Fe se convirtió en un núcleo de producción triguera que creció de manera exponencial desde la década de 1870. Más allá de algunos años de sequías, inundaciones u otras externalidades, durante todo el periodo analizado los niveles de trigo producidos se mantuvieron en franco ascenso 4 Como epifenómeno de este ciclo de especialización cerealera, emergió en dicha región una serie de emprendimientos manufactureros que buscaron generar valor agregado en la producción agrícola, entre los que se destacó la industria molinera. Si bien los primeros molinos harineros a tracción hidráulica o a vapor ya existían en algunas ciudades de Argentina al promediar el siglo XIX, el incremento de unidades productivas con maquinaria moderna construidas en las colonias santafesinas generó un punto de inflexión en la actividad ${ }^{5}$ Fue en esos pequeños poblados de la campaña provincial donde comenzaron a extenderse los modernos sistemas de molienda, que permitieron producir harinas cada vez más refinadas y blancas, ganando además eficiencia en la producción (Djenderedjian et al., 2010; Fernández, 1999; Gallo, 1983). De tal manera que los quince molinos que había en 1872 pasaron a 39 en 1880 y 70 en 1887. Para el año 1895, 69 de los 74 molinos existentes en la provincia utilizaban el sistema de molienda por cilindros, lo que ubicaba a Santa Fe como líder en esa tecnología en Argentina 6

La cercanía con las sementeras de trigo y el aprovechamiento de los canales de comercialización abiertos por el auge de la producción cerealera permitió a los molineros santafesinos ir conquistando numerosas plazas que tradicionalmente habían sido cubiertas, sobre todo, por harinas extranjeras y por la producción local inmediata de menor calidad. Un estudio que analizó la correspondencia comercial de un molino santafesino advierte de la expansión geográfica que lograron estos establecimientos desde la década de 1880 (Martirén, 2015). Hacia finales de la década de 1870, las unidades de molienda equipadas con tecnología de punta podían abastecer la demanda interna e incluso algunas plazas de Brasil. El año 1879 resultó un punto de inflexión: además de realizarse los primeros envíos al exterior, las harinas importadas prácticamente desaparecieron de los mercados locales (Djenderedjian et al., 2010; Fernández, 1999).7

Ya en la década de 1880 las urbes cercanas y los mercados brasileños habían acaparado la atención de la oferta de harinas santafesinas. Empero, el desarrollo de un extenso parque ferroviario sobre la región pampeana promovió costos decrecientes en los fletes, lo que permitió abaratar el traslado de los trigos desde la campaña y, como consecuencia, impulsó la construcción de molinos en los principales centros de consumo y exportación (las ciudades portuarias de Rosario y Buenos Aires). Pese a que el aumento de dicha infraestructura quitó a los molinos santafesinos una porción de la demanda en las mayores plazas de consumo -especialmente la ciudad de Buenos Aires

\footnotetext{
${ }^{4}$ A diferencia de otras provincias pampeanas, las estadísticas sobre la producción triguera de Santa Fe son muy completas desde la década de 1870. Sobre dicha tendencia, en 1872, la cosecha registrada fue de 11857 toneladas; en 1878, de 56 289; en 1882, de 156 999; 1887 ascendió a 470131 y en el último año del periodo analizado, 1895, la cosecha fue de 1200000 toneladas, en Martirén (2016, apéndice).

${ }^{5}$ Las estadísticas disponibles informan de un aumento considerable en la cantidad de molinos y en la capacidad instalada para la producción de harinas en las colonias ya desde mediados de la década de 1870. Un hecho interesante y anecdótico que ilustra la importancia que tuvieron las colonias en el cambio técnico que atravesó la molinería argentina -debido al auge triguero que estaban experimentando- fue el caso del Molino Bauer \& Sigel, que en 1876 tuvo una premiada participación en la Exposición de Filadelfia. Se sugiere la consulta de Zeballos (1894, p. 60), donde vuelca sus impresiones al respecto.

${ }^{6}$ Sobre el proceso de cambio tecnológico en la molienda, véase Djenderedjian et al. (2010, t. II, pp. 541-554).

${ }^{7}$ Gabriel Carrasco, estadístico y director del censo provincial de 1887 opina al respecto: "Hasta 1860 el pan que se comía en Santa Fe, era elaborado casi en su totalidad con harinas de otras provincias y hasta de Chile y California! En 1887, la producción de trigo en esta Provincia ha subido a cuatrocientos setenta y siete millones de kilogramos y existen 3 molinos a sangre, 4 a agua y 63 a vapor, con una fuerza de 1.664 caballos." (Carrasco, 1888, p. 109).
} 
y su hinterland-, les abrió a la vez el camino hacia nuevos mercados del interior -sobre todo el norte del país - lo que impuso un cambio de estrategia. En esa nueva coyuntura la provincia de Tucumán se convirtió en un objetivo para la colocación de las harinas, ya que el auge logrado allí por la industria azucarera había propiciado la apertura de sólidos canales de comercialización y nuevos corredores ferroviarios, como veremos más adelante ${ }^{8}$

\section{LA COMERCIALIZAGIÓN: UNA VARIABLE CLAVE EN LA CONSTRUCGIÓN DE MERCADOS Y EL CRECIMIENTO ECONÓMICO A FINALES DEL SIGLO XIX}

En los últimos años se ha desarrollado una renovada literatura teórica que interpreta al mercado no ya como la confluencia de fuerzas impersonales, sino como una construcción social, por lo que buscan rever algunos ejes temáticos y recuperar el interés por los actores en la coordinación de los canales de distribución. Desde esta óptica, los intermediarios y su participación en la economía han tenido una creciente atención (véanse Fernández, 2001; Fernández y Lluch, 2008; Lluch, 2015, pp. 13-22). La pregunta subyacente es por qué existen los intermediarios si el mercado, en teoría, es eficiente en la asignación de recursos. En términos generales, se debe a que los agentes cotidianamente implicados en el comercio encuentran altos costos de transacción en relación con los que tienen las firmas intermediarias. Por consiguiente, se vuelve altamente probable que los productores terminen operando con los consignatarios y comercializadores, actores centrales en el proceso de construcción y dinamización del mercado masivo de productos de consumo. Sus principales funciones podrían sintetizarse en la reducción de la búsqueda y contacto de potenciales clientes, la negociación de precios y cantidades, la concreción de las transacciones, y la reducción de los costos de información y comunicación a través de su experiencia y sus conocimientos de los mercados y entornos empresariales (véanse Casson, 1998; Cosimano 1996; Jones, 2003).

Con estos postulados, proponemos que el crecimiento exponencial experimentado por la economía argentina y, en este caso particular, por la industria harinera desde la década de 1880, impulsó y demandó una densa red de intermediarios profesionalizada y adecuada a las nuevas condiciones del contexto. Los crecientes volúmenes de producción debieron ser dirigidos hacia las plazas de consumo por estructuras de intermediación, logística y transporte cada vez más modernas y eficientes. El crecimiento económico promovió la expansión del mercado de alimentos y, por ende, la conexión entre productor y cliente se hizo cada vez más laxa. La posibilidad de garantizar la calidad de la mercadería fue más endeble, o bien, la estabilidad de la cadena de pagos incrementó su vulnerabilidad. Fue en estos puntos donde los intermediarios encontraron nichos donde especializarse y, en tal sentido, dinamizar la comercialización de estos bienes. Aportaron un interesante paquete de servicios que se volvió indispensable para tener competitividad en esta confluencia de mercados regionales: ofrecieron elementos clave como la búsqueda y conexión de los clientes, el ofrecimiento de garantías de pago, crédito comercial, adelantos sobre consignaciones, logística para el transporte y acopio de los productos. En definitiva, si emergieron al calor de esta expansión, se volvieron a la vez indispensables para sostenerla y ampliarla (Lluch, 2015).

\footnotetext{
${ }^{8}$ A modo de referencia, en 1869, durante la etapa previa al despegue azucarero (1876-1895), Tucumán tenía una población que rondaba los 109000 habitantes. En 1895, con la agroindustria ya consolidada, su población prácticamente se duplicó, alcanzando casi 216000 habitantes. En este último año representaba la sexta provincia más poblada entre las catorce provincias históricas, la capital federal y nueve territorios nacionales (República Argentina, 1899, p. CLXIV).
} 
Un proceso de crecimiento tan versátil necesariamente tuvo que estar acompañado por importantes cambios en la actividad comercial. En el caso de las harinas, la oferta del producto había estado garantizada durante el siglo xIx por Chile y Estados Unidos, además de reducidos aportes de la región de Cuyo, Córdoba y algunas provincias norteñas (Djenderedjian et al., pp. 572-575). A medida que el proceso de colonización agrícola santafesino tomó fuerza y se fue consolidando como el principal polo triguero a nivel nacional, los molinos que allí surgieron iniciaron una fuerte competencia a la antigua oferta. Con el crecimiento de la producción, los circuitos mercantiles asociados a este producto tuvieron que mutar y adaptarse al nuevo contexto. En consecuencia, las cadenas de comercialización lograron estructuras más complejas, y un grupo de intermediarios con características distintivas pasó a desempeñar un papel clave en el mercado de este polvo. Surgieron así nuevos agentes especializados en el comercio -los consignatarios- que dinamizaron por completo la operatoria e impulsaron la actividad de los molinos (Martirén, 2015).

Las condiciones para la expansión de la agroindustria anteriormente explicitadas eran requisitos indispensables, pero, a la vez, insuficientes. Fue preciso construir un nuevo mercado masivo de las harinas, proceso en el que actuaron de manera determinante los agentes intermediarios y su intrincada red de contactos, además de contar los molineros de las colonias santafesinas con una estructura y un costo de oportunidad más bajo que el de las harinas de otras regiones y de procedencia foránea. De esta forma, la producción de Santa Fe logró acaparar la demanda interna mediante la calidad, pero también a bajos precios. Ahora bien, ¿cómo se estructuró la comercialización de los productos en mercados distantes, particularmente el norte del país? En este punto influyeron varios factores, aunque la modernización de la infraestructura de transportes se volvió un aliado central de la nueva red de comercialización y del nuevo ciclo de expansión productiva.

El factor ferroviario marcó dos etapas en el comercio de bienes de consumo masivo en general, y, en particular, en el abasto de las harinas en las plazas norteñas, con efectos más visibles en Tucumán. La primera se dio entre mediados de la década de 1870 e inicios de la década de 1890. Comenzó con el arribo del Ferrocarril Central Norte en 1876 -posteriormente privatizado y renombrado Ferrocarril Central Córdoba (en adelante FCCC) - que conectó a Tucumán con la ciudad de Córdoba. Ello convertía a esta última en el primer destino del azúcar norteño y, a la vez, en nexo en el recorrido del dulce hacia los mercados mayores de Rosario y Buenos Aires $9^{9}$ Un dato que se debe observar es el contraste del ancho de vía entre ambos tendidos: a diferencia de la vía ancha del Ferrocarril Central Argentino (el tramo Rosario-Córdoba), el tendido que iba hacia el norte era angosto, lo que generaba costos adicionales para el transporte de las mercaderías (descarga, almacenaje, traslado, cambio de vías y nueva carga de las remesas). Córdoba disfrutó de una situación de privilegio en cuanto a la logística del transporte, captando parte del ingreso azucarero y, a la inversa, de los demás productos que se enviaban desde los puertos de Buenos Aires y Rosario al interior mediante el cobro del flete y trasbordo (Sánchez-Román, 2005, p. 99).

No obstante, si la construcción de esa línea permitió colocar a costos decrecientes el azúcar en las plazas comerciales del litoral pampeano, también abrió la puerta de los mercados norteños al ingreso masivo de las harinas que se producían en la región central, en particular la embrionaria

\footnotetext{
${ }^{9} \mathrm{Al}$ momento de la puesta en funciones del tramo Córdoba-Tucumán, el presidente Nicolás Avellaneda, en su discurso del 7 de octubre de 1876 señalaba: "[el ferrocarril] que hoy inauguramos... ha sido acogido entre transportes de entusiasmo, porque viene en hora oportuna, cuando las industrias cereadas [sic] lo esperaban para dar otros mercados a sus productos. El azúcar tucumano se consume después de veinte días en Córdoba y llega en estos momentos al Litoral. La apertura de esta vía es así bajo todos los aspectos un acontecimiento nacional, y su influencia se hará muy pronto sentir en los consumos del país entero.” República Argentina (1876, p. 7).
} 
producción harinera cordobesa ${ }^{10}$ Aunque una vez que los agentes de comercialización lograron aceitar la dinámica del transporte, y que el abaratamiento de los fletes promoviera la instalación de molinos en Rosario y Buenos Aires, las harinas santafesinas comenzaron también a orientarse hacia las plazas norteñas. Tal cual, sin abandonar el suministro a las grandes urbes, se volvieron importantes proveedores de los centros de consumo en el interior del país, con una fuerte competencia a los tradicionales abastecedores cordobeses y desplazando progresivamente a los productores locales (véase gráfica 1 ).

La utilización de modernas instalaciones de molienda y el acceso a un trigo local con estándares de calidad internacionales permitieron a los molinos llevar un producto que progresivamente fue ganando los mercados del norte del país. No resulta casual la aparición del rubro de harinas santafesinas en los listados de precios y anuncios publicados en los diarios tucumanos a mediados de la década de los años 1880 11 En términos cuantitativos, las escasas estadísticas disponibles también apuntan a esa dirección. Como se desprende de la gráfica 1, las llegadas de harinas por vías férreas que partían en la región pampeana hacia Tucumán (y particularmente las que servían a las colonias de Santa Fe) crecieron considerablemente ${ }^{12}$ En los años 1880, fue el FCCC el que monopolizó la oferta, por lo que, en un principio, el derrotero de las harinas santafesinas era extenso, en tanto debían llegar por vía fluvial al puerto de Rosario, y desde allí partir por ferrocarril a Córdoba y luego a Tucumán. Además, durante esa década la persistente falta de material rodante y los incrementos en los costos de flete y trasbordo, obstaculizaban los flujos comerciales hacia las principales plazas, ya sea desde el norte hacia los puertos o a la inversa (Lahitte y Correa, 1898; Rodríguez-Marquina, 1889), de modo que la expansión de las harinas hacia nuevos mercados del interior no estuvo exenta de dificultades.

Por entonces, a la iniciativa de erigir una refinería de azúcar en el puerto de Rosario (proyecto impulsado en 1886 por el destacado empresario y financista Ernesto Tornquist, concretado en 1889), le resultó indispensable evitar el obligado paso del azúcar por Córdoba, en la medida que los ingenios norteños serían los abastecedores del insumo necesario para elaborar azúcares refinados para el consumo interno. Así, esta nueva diagramación de la estructura productiva azucarera en el país, junto con la necesidad de dinamizar las colocaciones de productos pampeanos en los crecientes mercados septentrionales influyó, sin dudas, en la construcción de líneas de conexión directa (véase mapa 1 ).

Esta segunda etapa se abrió entre 1891 y 1892, con la puesta en funciones de dos nuevos tendidos que conectaron directamente a Tucumán (y, por su intermedio, a las plazas aledañas) con la región pampeana, sorteando el territorio cordobés. Desde entonces, la capital azucarera contó

\footnotetext{
${ }^{10}$ Durante las décadas de 1870 y 1880 , es frecuente encontrar en la prensa tucumana anuncios y cotizaciones de polvos provenientes de estas regiones. Además, destacados comerciantes de Córdoba trabajaron con azúcares y aguardientes provenientes del norte y colocaron, entre otros bienes, harinas en las plazas septentrionales con su base en Tucumán. Inclusive, fueron propietarios de almacenes de acopio y venta en la capital y en la campaña de esta última provincia. Cédulas del Segundo Censo de la República Argentina. Boletín Comercial, núm. 41. Censo Nacional de 1895, AGn. Sobre el vínculo comercial entre Córdoba y Tucumán durante este periodo, Converso (2001) y Valdemarca (2003).

${ }^{11}$ Harina Santafesinas. Harina Fénix y cilindros hay en venta en casa de José B. Verci, El Orden, 20 de marzo de 1885.

${ }^{12}$ Es importante señalar que, posiblemente, estas estadísticas subdimensionen las cargas transportadas, por lo menos en la medición de 1895 para el Ferrocarril San Cristóbal. En ese año declaró un total de 339 toneladas mientras que, según datos de 1893, el transporte de harinas hacia Tucumán sobrepasó las 4000 toneladas. Puesto que para esa fecha no contamos con datos de las demás líneas férreas, optamos por no incorporarlo.
} 


\section{GRÁFICA 1. EVOLUCIÓN DE LAS GARGAS DE HARINA ARRIBADAS A TUCUMÁN POR VÍAS FÉRREAS CON ORIGEN EN LA REGIÓN PAMPEANA (EN TONELADAS)}

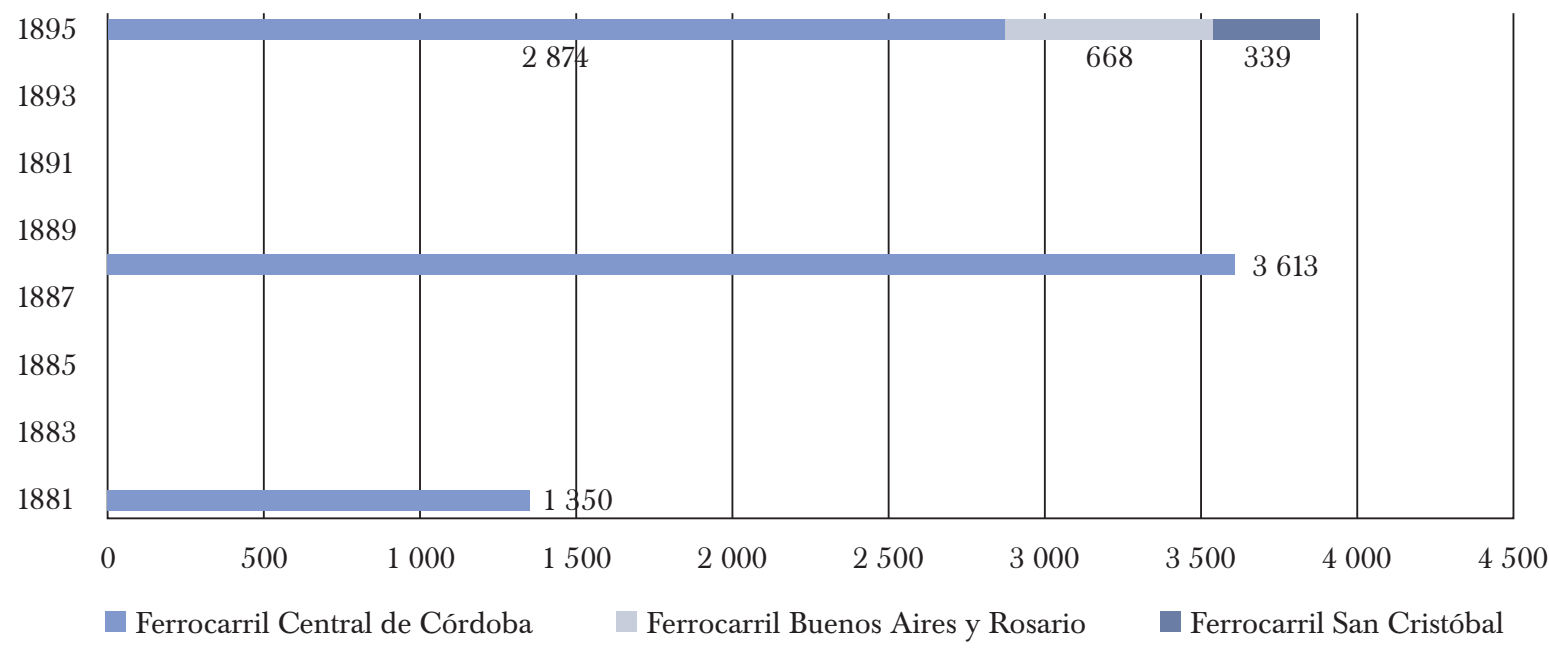

Fuentes: elaboración propia con base en Provincia de Tucumán (1884, pp. 75-76), Dirección General de Estadística (1896, pp. 333-351). Rodríguez-Marquina (1889, p. 178).

con tres líneas que la vinculaban con la región central: el FCCC, el Ferrocarril Buenos Aires y Rosario y el Ferrocarril San Cristóbal. Estos últimos atravesaban el corazón de las colonias de Santa Fe y dividían sus tendidos en la colonia Rafaela. Posiblemente el tendido del Ferrocarril San Cristóbal con su paso por San Cristóbal- haya sido proyectado con el objetivo de tocar las colonias ubicadas más al norte, atravesar regiones leñeras e ingresar a Tucumán por el naciente, una de las zonas con mayor concentración de ingenios azucareros de la provincia. Así, la vinculación directa con Rosario, la notable reducción de las distancias y la consiguiente merma de los costos de transporte, obligó al FCCC a adecuar su esquema tarifario para mantener competitiva la línea (Lahitte y Correa, 1898). Si bien es posible observar que las harinas santafesinas también utilizaron estas dos nuevas redes troncales, pasando a transportar $26 \%$ de toda la oferta en 1895, resulta evidente que no fue desplazado del flujo comercial de mercaderías hacia el norte, hacia los puertos o hacia el interior del área pampeana.

Si ello oxigenó a los ingenios tucumanos en una nueva coyuntura -sobre todo por la aparición en escena de la Refinería Argentina, que los obligaba a reconfigurar el tablero de estrategias de colocación de productos, enviando azúcares crudos para refinar y azúcares blancos molidos para el consumo (Guy, 1981; Moyano, 2012) - en el caso de las harinas, el impacto de este nuevo corredor ferroviario fue muy fructífero, ya que les permitió consolidarse en las plazas norteñas-. Como ejemplo de este proceso, del análisis de la correspondencia de los molinos santafesinos de Milesi y de Denner, se desprende que la opción por los intermediarios para sus colocaciones mediante las nuevas vías férreas pasó a ser moneda corriente. Según los informes oficiales, a fines de la década de 1880 ya se había consolidado una sólida oferta de harinas de alta calidad desde las colonias de 


\section{MAPA 1. INFRAESTRUCTURA FERROVIARIA QUE VINCULÓ A TUCUMÁN Y EL NORTE CON LAS COLONIAS SANTAFESINAS Y LAS PRINCIPALES CIUDADES DEL ÁREA PAMPEANA}

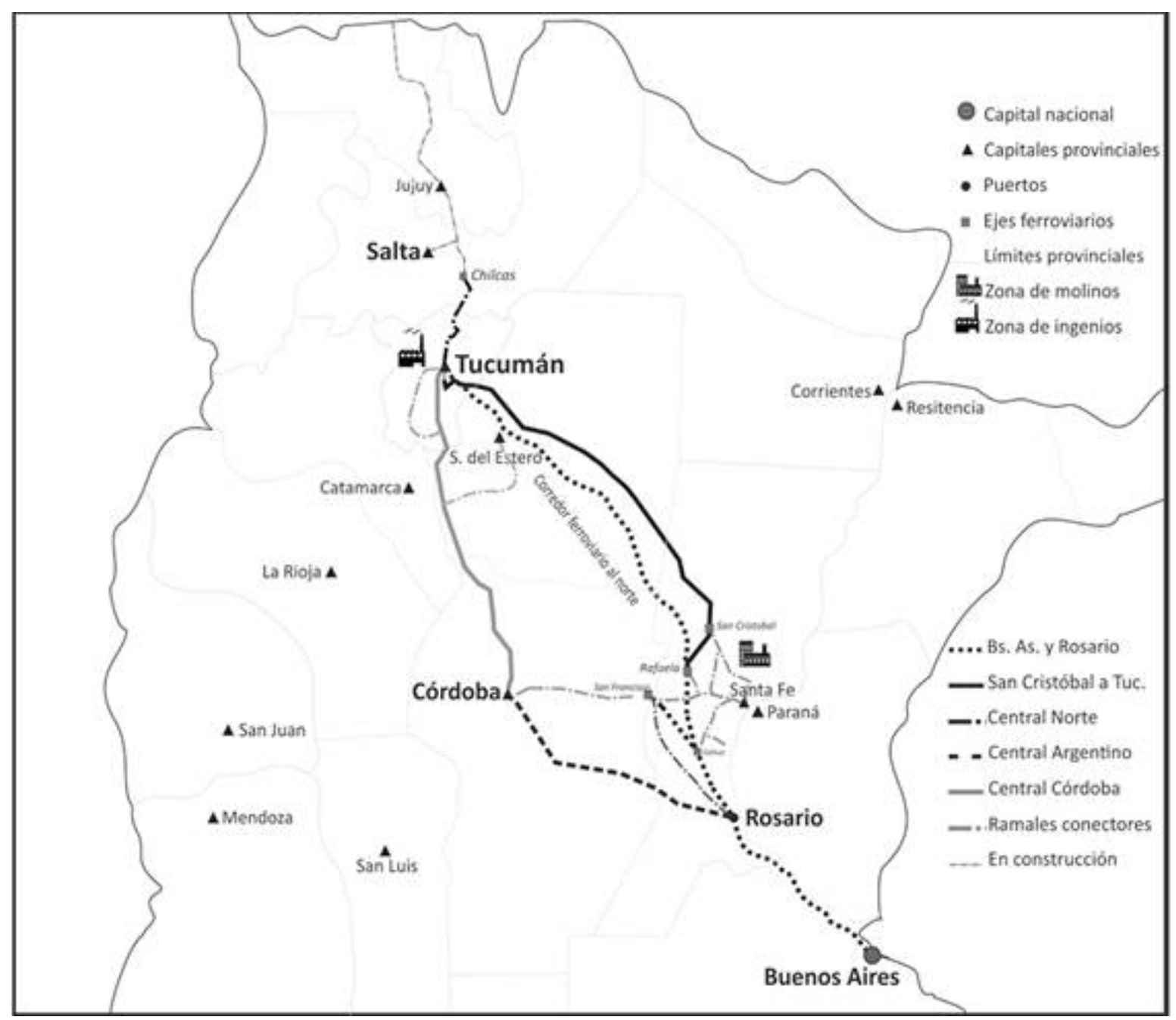

Fuente: elaboración propia con base en Chavanne (1889), Lahitte y Correa (1898).

Santa Fe hacia los mercados norteños a precios competitivos ${ }^{13}$ Lamentablemente, la calidad de las estadísticas agregadas sobre envíos-arribos de harinas a Tucumán (y por extensión a las provincias vecinas) es bastante limitada. Tal como señalamos, sólo se han localizado datos comparables de envíos por vías férreas para 1881, 1888 y 1895. Más allá de esto, se nota una tendencia ampliamente creciente en estas remesas, que a la vez se ve reflejada en la prensa periódica tucumana y en los informes oficiales, como el referido jefe de Estadística de Tucumán. Una información que refuerza nuestras proposiciones, fue aportada por Alois Fliess (1892) en su trascendental obra encargada por el Ministerio de Hacienda de la Nación. Según los datos recabados durante el año 
1891, del total de las harinas que se exportaron desde Santa Fe por vías fluviales y terrestres, $65 \%$ fue destinado por ferrocarril a las provincias del interior del país (Córdoba y Norte) (Fliess, 1892, p. 206) 14

La exploración de los archivos de los molinos también permite vislumbrar no sólo la importancia que tenía el norte como plaza de demanda, sino también el entramado de comerciantes que operaban en los circuitos mercantiles. Como ejemplo, un lugar tan ignoto como estación Chilcas, en la provincia de Salta (que hasta 1891 -y durante un largo tiempo - había sido la punta de rieles a partir de la cual se conectaba con la capital salteña y la ciudad de Jujuy, como resultado de la paralización de las obras de prolongación del tendido férreo), pasó a ser un centro de acopio y distribución con representantes de comerciantes tucumanos. La importancia adquirida por Chilcas muestra no sólo el peso que tuvieron los intermediarios en la conformación de nuevas plazas de consumo para las harinas santafesinas, sino también que aprovecharon eficientemente las oportunidades de comercio que ofrecía el nuevo corredor ferroviario. De esto se desprenden dos efectos adicionales: por un lado, la producción de Córdoba no pudo ofrecer una seria competencia a los embarques de harinas de Santa Fe, lo que se reflejó en la caída de las remesas de esa provincia, sobre todo a partir de 1885-1890. Por otro, la afluencia de harinas de calidad supuso un duro golpe a la incipiente industria molinera tucumana 15

\section{Una mirada a los agentes del proceso de comercialización y articulación de mercados}

Hemos anticipado que el auge molinero derivado de la expansión agrícola pampeana logró promover una densa red de comercialización e intermediación en varias plazas del país. Hasta el momento evidenciamos, en términos generales, las características de esos canales de comercialización y algunas de las estrategias utilizadas para abastecer nuevas plazas de consumo. A continuación, pretendemos examinar con un mayor detalle el funcionamiento de estas estructuras a partir de un análisis enfocado en los actores, intentando dar cuenta del entramado de relaciones comerciales entre los molinos del nicho productor santafesino y la plaza de Tucumán -como centro de consumo y distribución hacia provincias aledañas-, identificando los agentes partícipes en ese mercado y los mecanismos de intermediación y ventas. Este sesgo analítico obedece, principalmente, a la relativa abundancia de datos recogidos en Tucumán como destino de las harinas, y por contar con fuentes contables de los mencionados molinos santafesinos.

\footnotetext{
${ }^{13}$ Resultan ilustrativas las impresiones de Paulino Rodríguez-Marquina, jefe de Estadística de Tucumán, quien señalaba en 1889: "La producción de trigo ha disminuido en los últimos años desde que algunos molinos cerraron sus puertas dejando la entrada expedita en el mercado a las harinas de Santa Fe, con las cuales se hace imposible toda competencia por la abundancia de trigo en sus extensas colonias y por sus importantes molinos montados a la altura de los adelantos más perfeccionados de la mecánica." (Rodríguez-Marquina, 1889, p. 292).

${ }^{14}$ Sobre este punto, Fliess afirmaba: "Por la situación privilegiada entre cuatro provincias muy ricas y sus puertos sobre el Paraná, ejerce la provincia [de Santa Fe] una muy poderosa influencia económica sobre las limítrofes. Es la proveedora de estas provincias y de todo el norte de la República del alimento más importante de la humanidad, el pan, y lo será hasta el centro de Bolivia y el este del Perú tan luego que la locomotora haya pasado las fronteras de estas repúblicas." (Fliess, 1892, p. 207).

${ }^{15}$ En 1889, Rodríguez-Marquina afirmaba: "En otros tiempos los molinos eran en la provincia una fuente de riqueza, pero desde que en Santa Fe se desarrollaron las plantaciones de trigo y la harina ha invadido nuestro mercado no tiene importancia" (Rodríguez-Marquina, 1889, pp. 322-323). En 1895, luego que las harinas santafesinas abastecieran una gran porción de la demanda norteña, Tucumán contaba con 18 molinos de los cuales menos de la mitad eran unidades rentables y lejos estaban de las escalas del parque molinero santafesino. Véanse Cédulas del Segundo Censo de la República Argentina. Boletín Industrial, núm. 32. Censo Nacional de 1895, AGN.
} 
En lo que respecta a las harinas introducidas en Tucumán, detectamos varias casas intermediarias de gran escala. A partir de la información contable de los molinos, pudimos identificar firmas tales como Hermann Altgelt y Cía., José Ocampo y Cía., que oficiaban como consignatarios en las grandes plazas de Buenos Aires y Rosario; Francisco Sáenz y Cía., de Rosario, o las cordobesas Heinz, Kurth y Cía. y Perea Muñoz. La contabilidad es vasta y figuran otras importantes casas. Pero lo que buscamos destacar es que estos agentes eran, a la vez, intermediarios de los productos tucumanos en los mismos mercados donde operaban con las harinas y también de una multiplicidad de géneros, tanto para las diversas plazas comerciales del interior del país como para el comercio exterior (Moyano, 2015). Vale decir que entre las décadas de 1880 y 1890, los grandes intermediarios que, hasta cierto punto concentraban diversos ramos del comercio puertas adentro, tuvieron como rubros predilectos a los azúcares y aguardientes en las mayores plazas de consumo, y a las harinas en los mercados norteños.

En este sentido, podemos formarnos una idea sobre un denso entramado de flujos de bienes controlados por los mismos actores. Necesariamente se deberá reforzar esta hipótesis con análisis de otros bienes de consumo, sobre todo con la producción azucarera. Pero el hecho que ubiquemos a estas y otras casas comerciales operando con azúcares y aguardientes tucumanos y harinas santafesinas, oficiando como intermediarios y representantes de harinas en Tucumán y como consignatarias de diversos ingenios en Rosario y Buenos Aires, o trabajando con harinas de las colonias y con azúcares en la plaza rosarina, sirven como ejemplos válidos para arriesgar la existencia de una red de intermediarios profesionalizada, adaptada completamente a las nuevas condiciones del contexto. Esto es, agentes versátiles y eficientes en los mecanismos de intermediación, y por ello, actores centrales en los circuitos de comercialización 16

Pese a la amplitud comercial de estas casas, no por ello debemos pensar que monopolizaban completamente el mercado. De acuerdo con la información de ambos molinos y la prensa tucumana, pudimos detectar a almaceneros y acopiadores tucumanos consignando o comprando y revendiendo harinas, como José Benci o Luis Monsegur ${ }^{17}$ almaceneros del interior de la provincia como Ignacio Toledo (Monteros, tercera urbe de Tucumán en términos de población); o corredores-intermediarios como Alejandro Posse, representante en la provincia de la harina marca Llave, y la firma Padilla y Helguera, con idéntico desempeño de las harinas San Cristóbal (en ambos casos, se trató de miembros de familias propietarias de ingenios, con cuyos azúcares también operaban). No faltaron almaceneros que operaban en provincias aledañas como Guillermo Augspurg (ciudad de Salta), Francisco Alvarado (Chilcas, en el centro sur de la provincia de Salta), o Francisco Pandolfi (Frías, en el oeste de Santiago del Estero, sobre la vía del FCCC).

\footnotetext{
${ }^{16}$ A título de ejemplo, la casa Brinkmann y Cía. tuvo agentes en Tucumán y contactó a los molineros con consignatarios menores o distribuidores en lugares recónditos, pero a la vez estratégicos, como el mencionado Chilcas. Además de oficiar como nexo, financió operaciones y fungió como garante ante cualquier eventualidad en el traslado del producto, lo que nos lleva a suponer que se trató de un agente clave para la vinculación de dichas plazas y el funcionamiento aceitado de estos mercados. Véase Archivo del Museo Histórico de Humboldt (AHH), Fondo Milesi, Correspondencia, Mazos 1887-1895.

${ }^{17}$ Entre 1885 y 1893 , en los listados de mercaderías despachadas en las estaciones de Tucumán y reproducidas en el diario El Orden, ubicamos a estos almacenes enviando con frecuencia harinas hacia la campaña tucumana y hacia provincias vecinas. Por desgracia, la calidad de la información nos impide confeccionar series consistentes de despachos o recepción de estos productos, en la medida que representan noticias discontinuas y con desagregación de datos variable (origen, cantidad, calidad).
} 
Por último, quisiéramos hacer mención a un caso que, a nuestro entender, reviste una importancia especial: la firma tucumana Pape Hnos., luego Ernesto Pape, una afamada panadería, cervecería, fábrica de galletas y depósito de harinas que contó con su casa central en la capital tucumana y con una decena de sucursales (principalmente panaderías) en todo el interior de la provincia. De acuerdo con la contabilidad de los molinos antedichos, pudimos determinar un trato directo con este empresario tucumano, sorteando la injerencia de los intermediarios. Este caso, pese a ser aislado, resulta elocuente al permitir dilucidar el universo de relaciones comerciales posibles a fines del siglo XIX. Evidentemente, la fluidez de los transportes (con dos líneas que conectaban directamente las colonias santafesinas con Tucumán, y otra a través de Córdoba), y la facilidad de las comunicaciones mediante el telégrafo, hicieron inevitable que tarde o temprano los extremos de las cadenas de comercialización se conectaran, una vez que se asentara en el tiempo una relación comercial. Pape, al tratarse de un panadero y vendedor de harinas, habría sostenido una demanda de materia prima con los molinos para el desenvolvimiento de su negocio. Una vez que se desarrolló una constancia en los pedidos y se aseguró la alta calidad necesaria de los polvos para la panificación, pudieron sortear la etapa de la intermediación, reducir los costos de transacción en ambos casos y apuntalar su relación comercial de forma directa.

En las operaciones de compraventa de harinas, los almaceneros no tuvieron una relación permanente con un sólo molino, sino que fue variable, siempre de acuerdo con la intensidad de la demanda, a las posibilidades de colocar un tipo de producto y, lógicamente, a los precios de venta. De todos modos, estas casas comerciales siempre estaban provistas de harinas de diferentes clases y lo publicitaban mediante avisos en la prensa local. ${ }^{18}$ En los casos en que trabajaron como consignatarios de los molinos, estos almaceneros ofrecieron una variedad de servicios, como búsqueda de potenciales clientes, negociación de los precios y, sobre todo, publicidad de los productos entre una clientela distante e inaccesible para los molineros santafesinos, que podía ser tentada por productos similares de otros proveedores. Por supuesto, las grandes casas consignatarias ofrecían un portafolio más amplio con la financiación como una de las aristas destacadas, concentrándose presumiblemente en la colocación de importantes remesas a consolidados clientes mayoristas e importantes depósitos de harinas en este espacio regional.

\section{ELEMENTOS PARA CORROBORAR LA INTEGRACIÓN DE LOS MERCADOS: UN ANÁLISIS DE LOS PRECIOS DE LAS} HARINAS EN LAS PLAZAS ATENDIDAS

El análisis del comportamiento de los precios en algunas plazas comerciales del país nos puede brindar más pistas acerca de los efectos reales que tuvieron estos intermediarios en la dinamización de los circuitos de comercialización y venta, y en la creciente articulación de estas regiones. Sobre este punto, es importante señalar que la convergencia de mercados no se basa solamente en una frecuencia de intercambios entre plazas distantes, sino que precisa como requisito sine qua non una cierta uniformidad. En este sentido, sólo determinando el grado de una conexión orgánica podremos aproximarnos al nivel de maduración de los intercambios mercantiles y, por ende, a la conformación de mercados integrados $\sqrt{19}$ Es innegable que el desarrollo del transporte ferroviario

\footnotetext{
${ }^{18}$ A modo de ejemplo, "Harinas Especiales. La casa del Sr. Vilfrid Baron [importante almacenero de Tucumán] ha recibido una gran cantidad de este artículo de los mejores molinos de Santa Fe, como ser las marcas Fénix Cero, Coronda y Lubary teniendo siempre en depósito permanente fuertes cantidades." El Orden, 27 de diciembre de 1887.

${ }^{19}$ Discusiones sobre las características de los mercados regionales y la construcción de un mercado nacional unificado pueden consultarse en Sereni (1980), Grosso y Silva Riquer (1994), y Berg (1995).
} 
se tradujo en un aumento de los flujos por los costos decrecientes que generó, cuyo resultado fue el impulso de la especialización regional (Arcondo, 1994, p. 41; Pollard, 1991, pp. 163-168; ). Pero más allá de que algunos estudios han centrado su atención en variables tarifarias, arancelarias e institucionales para explicar dicha integración -y, de hecho, creemos que fueron una invaluable contribución-, no responden interrogantes que consideramos centrales: ¿̇cómo se estableció ese flujo de bienes? ¿Cuáles eran los circuitos que conformaban el largo trayecto desde el productor al cliente? ¿Quiénes los coordinaron y desarrollaron? En definitiva, ¿cuál fue la función de los agentes del mercado en dicho proceso?

Por otro lado, no bastan las estadísticas de entradas y salidas de bienes para hablar de convergencias, sino que es imprescindible recurrir al sistema de precios, ya que su análisis y comportamiento en diferentes plazas regionales permite comprobar el grado de correlación (Arcondo, 1994, p. 40; Sereni, 1980, pp. 33-43, 60-62). Aunque en el periodo estudiado todo indica que el camino hacia la unificación del mercado nacional estaba en marcha, preferimos hablar de convergencia, confluencia o interconexión de mercados regionales, en la medida que en buena parte del territorio nacional aún carecía de la normalidad de los flujos mercantiles y, por lo tanto, de una organicidad de los vínculos comerciales basados en intercambios equivalentes. Es por ello que apelaremos al análisis del comportamiento de los precios de las harinas en tres importantes plazas: Santa Fe y Tucumán, centro productor y consumidor, respectivamente, y Buenos Aires, principal centro de consumo del país y formador de los precios de exportación.

$\mathrm{Si}$, como hemos visto, el accionar de los intermediarios y la modernización en el parque de infraestructura nacional promovió una dinamización de los intercambios, podría pensarse que el impacto también habría afectado a la cotización de los productos de las distintas plazas; esto es, que la diferencia de precios entre las harinas en Santa Fe (centro productor) y Tucumán o Buenos Aires (plazas de consumo), haya sido tendencialmente decreciente, aunque, por supuesto, nunca equiparables. Para probar esta hipótesis, hemos apelado a fuentes empíricas, confeccionando series de precios de harinas que cubren todo el periodo analizado, con la intención de observar el comportamiento de las cotizaciones y arriesgar posibles explicaciones (véanse gráficas 2 y 3 .

Los datos presentados muestran algunos puntos de interés. En lo que respecta a la década de 1880, vista desde el núcleo productor de harinas (Santa Fe), es evidente cierta dispersión de precios con Tucumán, pero no así con Buenos Aires, pese a que en los tres casos hay una marcada solidaridad en las tendencias. En esta última, la dispersión de precios fue relativamente más baja debido a que ya existían dinámicos circuitos de comercialización de alimentos por los crecientes volúmenes de trigo que se enviaban desde las colonias ya a mediados de los años 1870 . Esto había optimizado los fletes, las operaciones y la colocación del producto, además de haber fomentado la instalación de grandes molinos en dicha ciudad portuaria (Djenderedjian et al., 2010).

En Tucumán la situación fue distinta por dos razones principales. La primera afectó a la estructura de los mecanismos de comercialización, que debieron adaptarse a lo largo de la década al crecimiento de los volúmenes de harina enviados desde Santa Fe. Si bien las estadísticas han centrado su preocupación en las plazas de Buenos Aires y Rosario como principal destino de las ventas, vale destacar que entre 10 y $20 \%$ se dirigió hacia las provincias norteñas ${ }^{20}$ Como vimos,

\footnotetext{
${ }^{20}$ Estos guarismos son aproximados, basados solamente en los registros de arribo de harinas a Tucumán (véase gráfica 1. Desde luego, es imposible saber si estos datos expresan la totalidad de los envíos hacia esa provincia por vías férreas. Por tanto, para estimar qué porcentaje aproximado de harinas se dirigieron a esta plaza, cruzamos los datos de producción de harinas de Santa Fe en 1887-1888 y 1895, con información en la gráfica 1. Se puede notar que las remesas, al menos para esos dos años, alcanzaron cantidades parecidas a las enviadas por los molinos santafesinos hacia
} 


\section{GRÁFICA 2. PRECIOS DE LAS HARINAS DE PRIMERA EN SANTA FE, BUENOS AIRES Y TUCUMÁN (1880-1895) (PESO MONEDA NACIONAL) ${ }^{A}$}

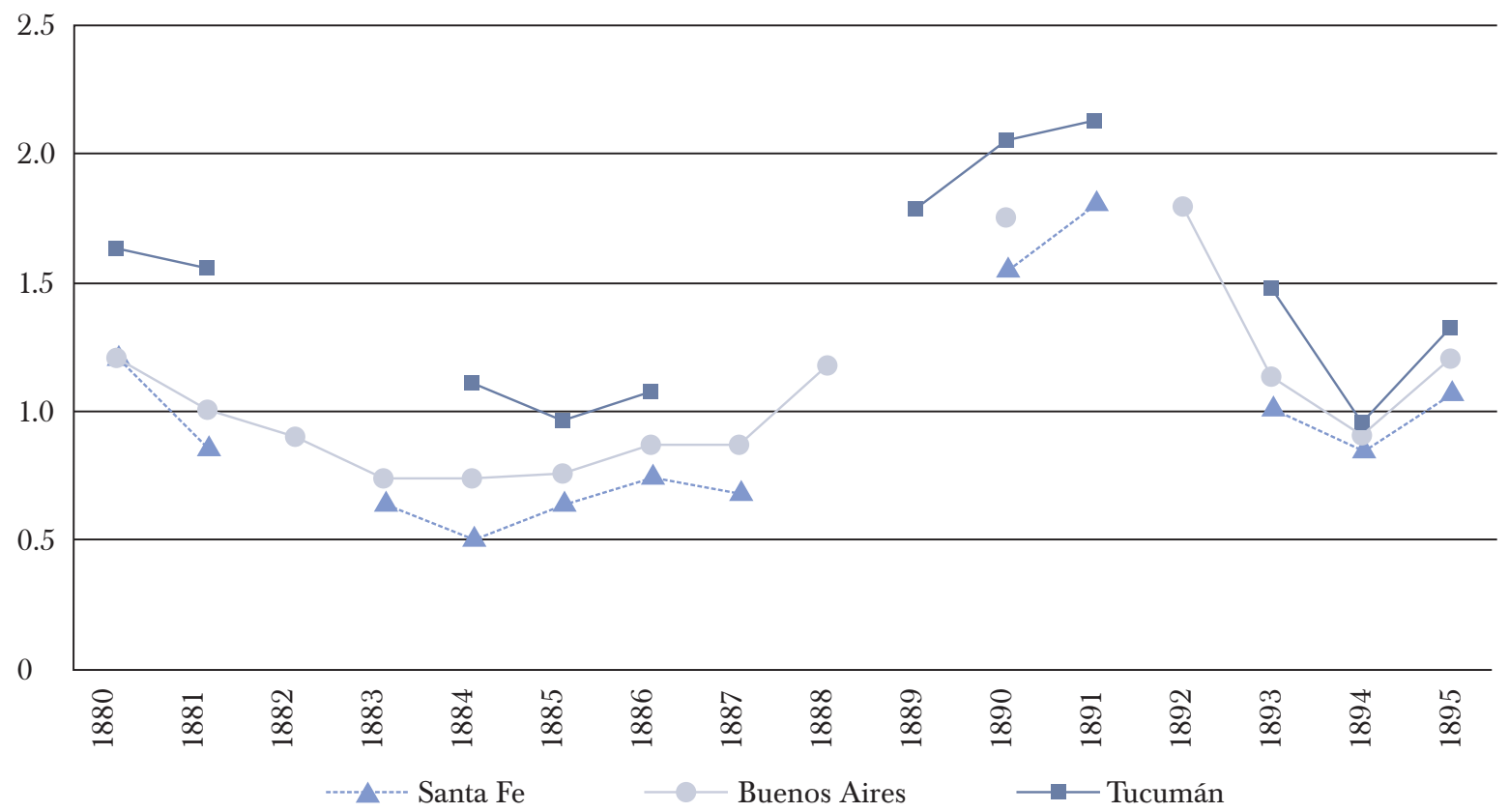

${ }^{\text {a }}$ El peso moneda nacional - a partir del cual se expresan los valores de esta serie - comenzó a circular desde 1833.

Nota: el peso moneda nacional comenzó a circular desde 1883 con una cotización a la par con el peso oro, moneda de cuenta y cambio del comercio exterior. Anteriormente, la moneda de mayor circulación en las provincias era el peso boliviano, por lo que, en las fuentes, la cotización de los productos figura bajo ese signo monetario. Para construir la serie en valores uniformes, hemos optado por expresarlos en peso moneda nacional, convirtiendo al trienio 1880-1883 a pesos oro.

Fuentes: elaboración propia a partir de los listados de precios, particularmente de la casa comercial Frías y Gallo (con casa matriz en Buenos Aires), reproducidos en el diario El Orden, Tucumán (diciembre de 1883; enero-diciembre de 1884 a 1895). Los precios de las harinas en la plaza tucumana fueron extraídos (además de El Orden) de El Republicano, Tucumán, meses de junio a diciembre de 1881. Los precios para Santa Fe en Libro Mayor 1886-1892; Libro de Consignaciones de 1884 y Correspondencia 1887-1895, Fondo Milesi, Archivo del Museo Histórico de Humboldt (АНн); Correspondencia, 1890-1894, Fondo Denner, AмcE; La Capital, 1884-1895 y El Colono del Oeste, 1880-1883. Los precios de la plaza de Buenos Aires también fueron corroborados con las series de precios de harina publicadas por Álvarez (1929).

las harinas santafesinas encontraron un mercado atractivo en términos de competencia, dominado por un suministro tradicional proveniente de Córdoba, de la región de Cuyo y algunas áreas del norte. Por lo tanto, una vez que los molineros santafesinos lograron optimizar el circuito de transporte por vía fluvial a Rosario y por tren a Córdoba-Tucumán, comenzaron a competir y a desplazar al tradicional abasto de este polvo en las plazas septentrionales. Como señalamos, varios factores permitieron este proceso: la incorporación de tecnología en la molienda, el acceso a un trigo barato y de alta calidad, las escalas de producción, la existencia de vías férreas desde Rosario a Tucumán, y la experiencia de los agentes de intermediación surgidos al calor de la expansión de la industria azucarera. En referencia a los precios, el hecho de contar con una oferta de trigos de 


\section{GRÁFICA 3. ÍNDICE DE DISPERSIÓN DE PREGIOS ENTRE PLAZAS DE SANTA FE Y} TUCUMÁN

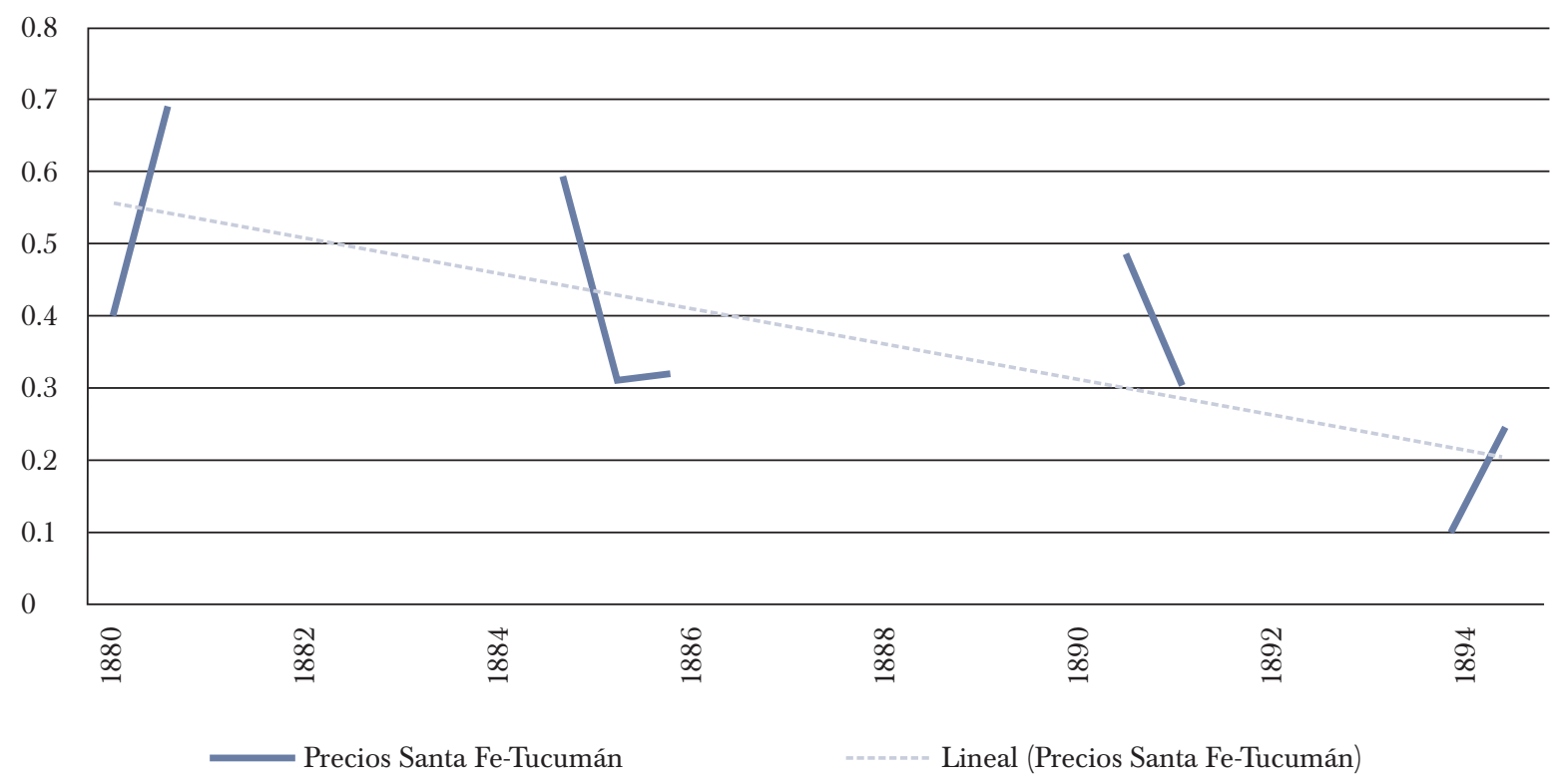

Fuente: elaboración propia con base en datos de gráfica 2

alta calidad a distancias cortas (de hecho, los molinos emergieron para generar valor agregado al trigo producido en las colonias) y avanzados sistemas de moliendas, les permitió a los molineros santafesinos costos de producción competitivos y economías de escala en relación con los tradicionales abastecedores que cubrían las plazas norteñas. El hecho de haber copado dichos mercados hacia fines de los años 1880 es un indicio bastante sugerente.

En relación con la calidad, no sólo el mencionado hecho de que en Santa Fe proliferase el sistema de molienda a cilindros es una evidencia concreta, sino también porque las harinas santafesinas tenían una destacada reputación en las competencias nacionales e internacionales en las que participaban (véase Djenderedjian et al., 2010, t. II, pp. 541 y ss.). No podremos saber, claro está, a qué estratos sociales iba dirigido el comercio de harinas santafesinas en el norte. Para ello, se precisaría de estudios sobre dietas y canastas de consumo en diferentes áreas, algo bastante alejado de los propósitos de este ensayo.

Por lo demás, a los fines de este trabajo resulta sugestivo que la dispersión de precios entre las plazas haya evidenciado un marcado descenso entre inicios y mediados de la década de 1880. Es probable que esta disminución, generada sin la incorporación de nueva infraestructura de transporte (que, como vimos, tuvo su influencia a partir de 1891), haya sido motivada por constantes mejoras en los mismos circuitos de comercialización.

mercados de exportación (básicamente a Brasil). Es de destacar que las exportaciones de harina al país vecino en el siglo XIX han concitado una amplia atención en la historiografía. Sin embargo, no tuvo la misma repercusión el comercio interior de polvos, pese a tratarse de volúmenes similares. 
La otra razón pudo tener una raíz monetaria. Pese a que Argentina puso en circulación una nueva moneda desde fines de 1883, varias provincias aún basaban su economía en monedas de plata boliviana. Contrariamente a lo que se cree, esta moneda, en su mayoría feble, continuó circulando en Tucumán hasta avanzada la segunda mitad de la década de 1880 y en Salta o en Jujuy por un periodo mayor, incluso sufriendo una fuerte y constante depreciación. Es decir, mientras en Santa Fe los precios de las harinas se imputaban en pesos moneda nacional desde 1884, en Tucumán la economía seguía basándose en el peso boliviano, que contaba en relación con el oro con un premio de más de 100 \% de su valor (Sánchez-Román, 2005). Así, resulta probable que los importadores tucumanos trasladaran la devaluación a los precios de las harinas, pues necesitaban de la nueva moneda nacional para pagar las remesas. No obstante, ello debió ser coyuntural ya que la dispersión tendió a disminuir.

En el periodo 1890-1895 el panorama fue distinto. Si las consecuencias de la crisis de 1890 parecieron ser marcadas en los años inmediatos (probablemente hayan generado impactos diferenciales en las distintas plazas), desde 1893 la divergencia disminuyó notablemente ${ }^{21}$ Respecto a Tucumán, es probable que hayan contribuido los nuevos tendidos ferroviarios. Según la correspondencia de los molineros, el precio del flete se abarató ostensiblemente, aunque no se puede pasar por alto la gran dinamización que existió en los mecanismos de comercialización a partir de la multiplicación de los agentes de intermediación, tal como vimos en el apartado anterior.

\section{DIFERENCIARSE DE LA COMPETENCIA: COMPLEJIZACIÓN DE LA OFERTA Y USO DE LAS MARCAS}

Hasta ahora analizamos la estructura de comercialización de las harinas y comprobamos el peso cualitativo de los comerciantes en la conexión interregional, mostrando cuantitativamente la efectiva solidaridad en las tendencias de los precios entre diferentes plazas en 1880-1895. Empero, no debemos perder de vista que, a medida que nos acercamos al final del periodo estudiado, los productos ofrecidos, aparentemente uniformes, en realidad fueron adquiriendo una mayor complejidad y diferenciación. No nos ocuparemos aquí de explicar si fue la demanda la fuerza motriz que impulsó estas transformaciones, o desde la oferta se buscó, mediante la calidad, ocupar mayores porciones del mercado. Lo que nos interesa destacar, y a la vez sirve como puerta para una futura investigación, es que los polvos santafesinos lograron paulatinamente mejores estándares de calidad y, por lo tanto, una significativa distinción gracias a la incorporación de sistemas de molienda europeos, lo que indefectiblemente impactó en las formas de comercialización. Esto planteó el desafío de diferenciarse de los productos de competencia y a la vez de ganar nuevos nichos en el mercado de bienes de consumo masivo. Algo que no puede pasar desapercibido es la temprana utilización de marcas de fábrica o marcas de origen en procura de destacar las particularidades intrínsecas de los productos. Es decir, la documentación nos ha presentado evidencias de una marcada preocupación por el etiquetado, rotulación o el registro de marcas en las harinas santafesinas ya a fines de la década de 1880 .

$\mathrm{Al}$ respecto, Andrea Lluch (2013) realizó una pormenorizada investigación sobre las marcas registradas y el uso que les dieron los comerciantes del interior pampeano en las primeras décadas del siglo xx ${ }^{22}$ De sus conclusiones nos interesa destacar que la aparición de la marca comercial

\footnotetext{
${ }^{21}$ Este fenómeno de reducción de la dispersión de los precios también se dio desde 1893 en el mercado de trigos, particularmente en las plazas de Santa Fe, Rosario y Buenos Aires. Véase Martirén (2016).

${ }^{22}$ En los últimos años, el análisis sobre la función de las marcas en la comercialización de productos ha cobrado un notorio impulso. Véase Lopes y Duguid (2010).
} 
fue un proceso gradual y variable, aun dentro de los productos genéricos, y que estuvo asociado con múltiples cambios: modos de producción-distribución de acuerdo con el tipo de producto y empresa, difusión de nuevos métodos de ventas, variaciones en el nivel de ingresos y el grado de urbanización. En nuestra aproximación a la temática nos centramos en un momento anterior (1880-1895) en un producto que fue adquiriendo una marcada complejización. Apuntaremos específicamente a los cambios registrados en la oferta a través de la incorporación de nuevos métodos de producción, cuya amplia diferencia se vio reflejada en la demanda y en el precio, y que tanto productores como comerciantes buscaron destacar.

Cuando el FCCN era el único nexo entre Tucumán con el área central del país, abundaban en los avisos de la prensa local referencias al origen de los productos, verbigracia harinas cordobesas, harinas y afrecho de San Juan o harinas de primera de Santa Fe. Sin embargo, a partir de mediados de la década de 1880 los avisos publicitarios y los listados de precios comenzaron a incorporar datos sobre la procedencia de las harinas junto a marcas de fábrica o el nombre de los molinos como origen distintivo. Esto claramente nos habla de un cambio en la oferta del producto, pasando de las harinas de primera típicas de la década de 1870 e inicios de la de 1880, a más clases y calidades superiores ${ }^{23}$ Aunque no fueron marcas registradas por las empresas, de algún modo oficiaban como una referencia para el cliente mayorista.

El hecho de que los molineros se preocuparan por publicitar sus productos de alta calidad junto al nombre del molino, nos habla de una competencia entre los productores y las distintas estrategias que utilizaron para identificar sus polvos por sobre los demás. Vale recordar en este punto que no fue casual que las harinas santafesinas fueran rotuladas sistemáticamente como de primera, no así sus concurrentes cordobesas o tucumanas. Se trató, como ya se señaló, de un producto realizado con un trigo de alta calidad y con un sistema de molienda sofisticado, que le permitió llegar rápidamente a los mercados de Rosario, Buenos Aires y Brasil. Al promediar los años de 1880, Santa Fe se había consolidado como el principal productor de harinas del país. Con la construcción de nuevos corredores férreos hacia el norte impulsados por la industria azucarera, se abrieron nuevos mercados que no desaprovecharon. Si bien los envíos no habrían superado el 20 \% de la producción total, este fenómeno muestra el lento proceso de integración de mercados regionales de alimentos que comenzó a aceitarse al calor del ferrocarril.

En la década de 1890 la competencia se recrudeció debido al perfeccionamiento de la fabricación y la elevada calidad de los polvos, irrumpiendo en el mercado las harinas cero, doble cero y flor ${ }^{24}$ Desde entonces, se puede identificar una doble tendencia. Por un lado, como señala Lluch (2013, p. 3) hizo su aparición la marca registrada. Al respecto, encontramos evidencias en la documentación del molino Denner, con cuadernos que presentaban a sus harinas bajo las marcas El Ganso Peleador (en este caso, con la aclaración de marca registrada) y Llave, como marca

\footnotetext{
${ }^{23}$ Harinas de Sta. Fe. De las acreditadas marcas Fénix, Molino Carcarañá. Ancla, Molino Santa Fé. Núm. 1, Molino Candelaria. El Orden, 15 de abril de 1885; dos años después se comercializaban las marcas Fénix, Coronda y Lubary, todas correspondientes a molinos santafesinos. El Orden, 27 de diciembre de 1887.

${ }^{24}$ Harina Leman 0, Las Tunas 0; Harinas Sunchales 0, Susana 0; Harinas Margarita 00 y 0, Harina Ceres $1^{\circ}$, también en todos los casos de molinos santafesinos. El Orden, 19 de abril de 1892, 10 de noviembre de 1894, y 15 de junio de 1895
} 


\section{FIGURA 1. MARGA REGISTRADA Y DE FÁBRICA DEL MOLINO DENNER (COLONIA ESPERANZA, SANTA FE, 1890)}

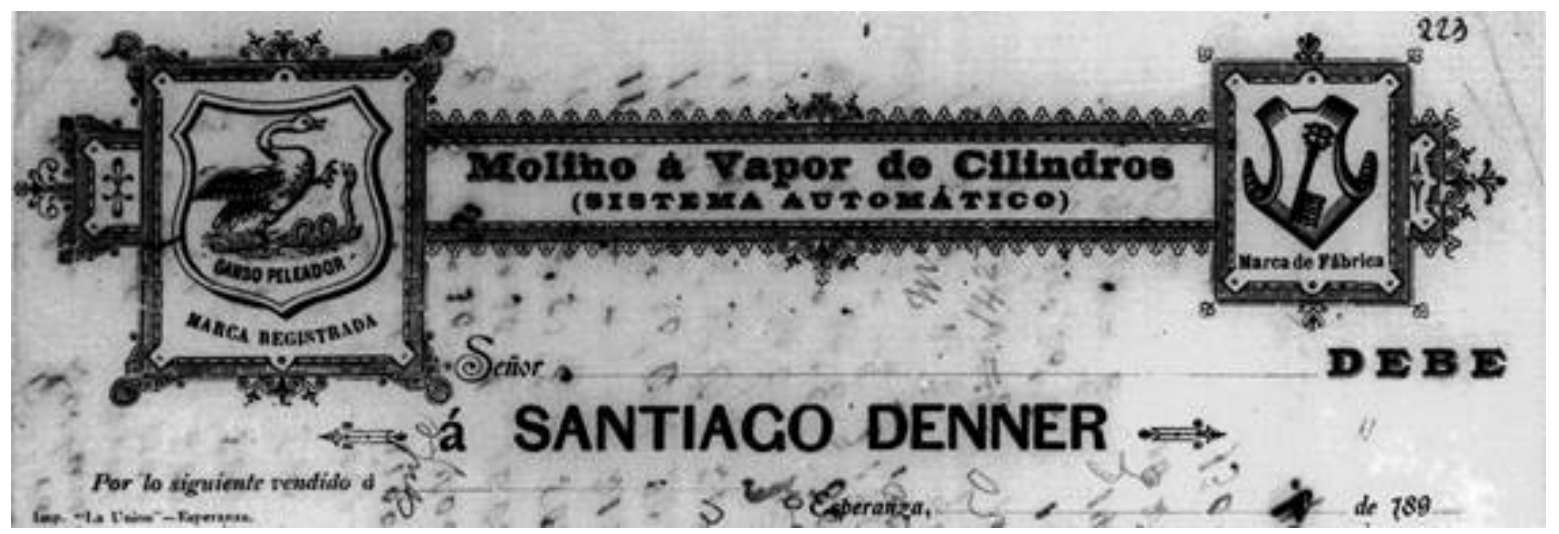

Fuente: Correspondencia, rollo 5, Fondo Denner. Archivo del Museo de la Colonización de Esperanza (AMCE).

de fábrica 25 Por otro lado, ubicamos también en los avisos publicitarios marcas que desconocemos si estaban registradas, pero que oficiaban como distintivos para diferenciar y dar a conocer el producto y su calidad (véanse figuras 1 y 2,26

La apelación a la marca como sello distintivo (fuese o no registrada) no resultó privativo de los productores, puesto que en varias ocasiones los mismos representantes de los molinos en Tucumán se preocupaban por dejar en claro qué harinas comerciaban 27 Resulta interesante el ya mencionado Alejandro Posse, quien operaba en Tucumán desde 1890 con las harinas marca Llave. Hemos encontrado esta información tanto en la correspondencia privada del molino como en la prensa tucumana. También, mediante el cruzamiento de datos, detectamos que los consignatarios Frías y Gallo, con oficinas en Buenos Aires y Rosario, tenían depósito permanente en Tucumán para los molinos Susana y Humboldt, justamente de propiedad de Milesi. Posteriormente fueron consignatarios de la marca Carcarañá. 28

\footnotetext{
${ }^{25}$ Correspondencia, marzo de 1891, Fondo Denner, Archivo del Museo de la Colonización (AMCE).

${ }^{26} \mathrm{Si}$ bien existía en Argentina una ley de marcas desde 1876, estas estrategias de diferenciación no necesariamente iban en línea con la cuestión legal. El periodo analizado coincidió justamente con el momento en el cual el tema de las marcas estaba atravesando un punto de inflexión (no sólo en el ámbito local, sino también en el contexto global): el aumento del comercio y del consumo había acelerado tanto la diferenciación de los productos como el desarrollo de un marco legal que acompañara el proceso. No obstante, se trató de un fenómeno con varias aristas, ya que a la par de la diferenciación registrada con instrumentos públicos, existieron herramientas de identificación de productos (etiquetado o labelling) que más allá de la cuestión legal, apuntaban más bien a estrategias de mercadeo para captación o fidelización de clientes. Este punto ha acaparado una gran atención en la literatura especializada en los últimos años, sobre todo en la europea y estadunidense. Véanse, entre otros, Moore y Reid (2008), Lopes y Duguid (2010). Para el caso argentino, Lluch (2013).

27 “[...] gran acogida está tomando la nueva marca San Cristóbal del molino de los señores L. Antom y Cía. [Santa Fe], quienes colocan fácilmente la marca 0". El Orden, 2 de junio de 1894; "El molino Margarita [Santa Fe] de propiedad del Sr. Brühl ha colocado fuertes partidas de la marca 0, la que no tiene gran salida por estar la plaza llena con la marca San Cristóbal, colocada por los Sres. Padilla y Helguera”. El Orden, 23 de junio de 1894.

${ }^{28}$ El Orden, 6 de junio de 1893 y 2 de mayo de 1895.
}

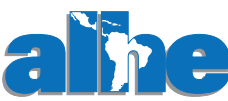




\section{FIGURA 2. INFORMACIÓN PERIODÍSTICA SOBRE LA OPERATORIA COMERCIAL DE LAS HARINAS SANTAFESINAS EN TUGUMÁN}

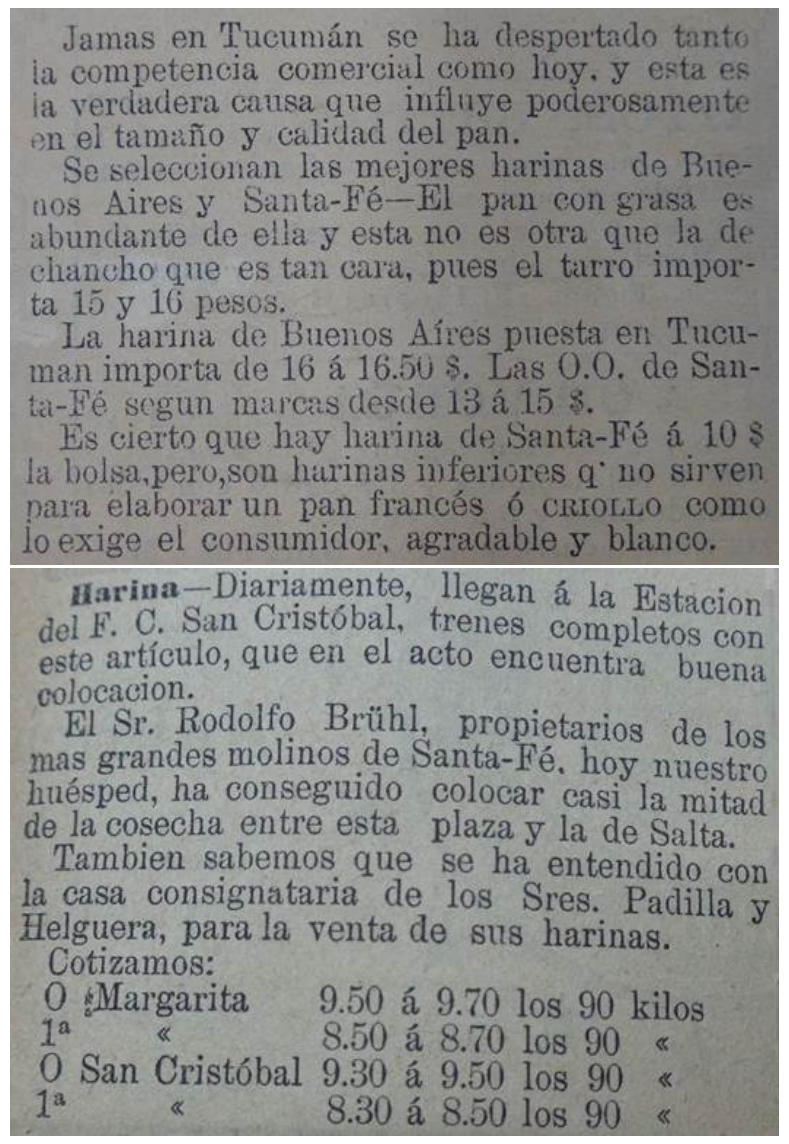

Fuente: El Orden (10 de marzo y 7 de julio de 1894).

Nuestro planteamiento cobra sentido si tenemos en cuenta que Tucumán representaba el eje de articulación comercial del norte del país, puesto que allí confluían las tres líneas férreas que conectaban esta región septentrional con el área central, donde no sólo los almaceneros locales comerciaban harinas hacia otras provincias aledañas, sino que las grandes casas del área pampeana tenían sucursales y los comerciantes de provincias vecinas contrataban los servicios de corretaje en la ciudad 29

\footnotetext{
${ }^{29}$ Un ejemplo es Rodolfo Brühl, un gran comerciante, molinero y empresario colonizador santafesino, de quien se informaba en la prensa tucumana: "El Sr. Rodolfo Brühl, propietario de los más grandes molinos de Santa-Fé, hoy nuestro huésped, ha conseguido colocar casi la mitad de la cosecha entre esta plaza y la de Salta." El Orden, 7 de julio de 1894. El caso es ilustrativo de una actividad muy particular específica de las colonias santafesinas. Al igual que Denner o Milesi, además de comerciante, era empresario colonizador. Es decir, formaban parte de un grupo de corredores locales que mediante su emprendedurismo lograron impulsar la formación de colonias y fomentaron la moderna industria molinera. No resulta casual que todos hayan comenzado como comerciantes o acopiadores de trigo. Estaban inmersos en una lógica comercial mucho más amplia, cuya modernización había sido impulsada por la expansión triguera, que supieron trasladar al rubro harinero. Véase Martirén (2016).
} 
Por supuesto, ningún producto que se vendía al menudeo estuvo exento de falsificaciones o mezclas que rebajaban su calidad. Pero tal habría representado la competencia entre los molinos en el mercado norteño que, en 1893, la firma propietaria del molino santafesino Carcarañá, Alejandro Maderna e hijos, fabricante de las harinas Patente y Fénix, decidió abrir una sucursal en Tucumán, según la prensa, porque dichas harinas eran objeto de groseras falsificaciones con el propósito de perjudicarlos o usufructuar de su aceptación ${ }^{30}$ Más allá de la veracidad o no de la información, lo cierto es que esta integración hacia adelante obedecía a la necesidad de sostener la calidad de su harina y la credibilidad y prestigio entre los compradores, otorgando una prueba más de la fuerte competencia de las harinas santafesinas en este mercado regional.

En definitiva, entre 1870 y 1885 las harinas tenían características medianamente uniformes. Pero a medida que incorporaron nuevos métodos de producción y mejoraron la calidad, se hizo difícil captar la preferencia de la clientela. Lógicamente, esta labor recaía en el intermediario como parte de su cartera de servicios, aunque los productores no se quedaron de brazos cruzados. De ahí la utilización de estos rótulos (de fábrica, de procedencia y, en menor medida, registrados) en los avisos y listado de precios de la prensa. Ciertamente, no otorgaban demasiada información, motivación o un mensaje concreto - parafraseando a Fernando Rocchi (1998, p. 550), no estaban dirigidos a la caza del cliente, como las estrategias de marcas o branding modernas- pues al tratarse de un comercio mayorista, resultaban innecesarias tales especificaciones. Pero sí buscaban diferenciar, dar notoriedad a la calidad del producto, y es aquí donde residió el poder de estos tipos de marcas, por lo menos, para este producto de consumo masivo a finales de la centuria.

\section{Conclusiones}

La agenda historiográfica actual sobre el periodo de la gran expansión económica de Argentina (1880-1914) está otorgando a la comercialización un lugar fundamental. En línea con los más recientes estudios sobre la temática que han mostrado aristas novedosas del proceso de crecimiento (véanse Frid, 2006; Lluch, 2004, 2013, 2015; Rocchi, 2016), este trabajo buscó aportar hipótesis alternativas y abrir nuevas agendas de investigación sobre un aspecto muy poco analizado de la expansión agraria en las postrimerías del siglo xix: la comercialización de harinas desde el principal centro productor hacia plazas de consumo del interior argentino.

Se trata de un tema difícil de abordar en tanto la documentación sobre este fenómeno es sensiblemente fragmentaria y dispersa para los años bajo análisis. No es casual, por ello, que gran parte de las investigaciones se haya centrado en aspectos puntuales de la producción, o bien, en la comercialización de los excedentes exportables hacia Brasil y la consiguiente conflictividad aduanera suscitada con el vecino país.

Sin embargo, en este trabajo hemos presentado evidencias que no sólo han dado parte del peso creciente que las plazas del interior tuvieron en las estrategias de comercialización de los molineros santafesinos, sino que sirve, al mismo tiempo, como punto de conexión para analizar cuestiones más profundas del proceso de crecimiento económico.

\footnotetext{
${ }^{30}$ El vespertino tucumano señalaba, en consecuencia: "En vista de este precedente, los nuevos dueños del Molino Carcarañá [...] no han omitido sacrificio alguno para rehabilitar la justa fama de sus harinas, haciendo en la actualidad una elaboración esmeradísima y estableciendo en esta plaza una sucursal, única que recibirá en lo sucesivo dichas marcas, garantiendo de este modo sus intereses y los de todos aquellos que se sirven de sus productos." El Orden, 26 de abril de 1893.
} 
En primer lugar, nos dice bastante sobre los mecanismos de reestructuración de las redes de comercialización. Ciertamente existieron vínculos entre comerciantes de la región pampeana y los norteños que se remontaban a fines de la época colonial. Pero la ampliación de la demanda de las plazas septentrionales, el aumento de la producción santafesina y la necesidad de dar continuidad al flujo de productos obligaron al cambio en las formas tradicionales de distribución, con la incorporación de una nueva logística, novedosas formas de mercadeo para colocar el artículo, atendiendo a la ubicación e intensidad de la demanda, y como consecuencia, la incorporación de nuevos agentes del comercio que pudieran crear estos enlaces. En este caso, se puede concluir que los intermediarios de las harinas no sólo llegaron al mercado norteño motu proprio, sino que utilizaron los canales de comercialización abiertos por el auge de la industria azucarera; en esencia, aprovecharon una infraestructura impulsada por otra agroindustria.

$\mathrm{Al}$ advertir la nutrida cartera de servicios de los intermediarios, vimos cómo en un mercado en expansión (tanto desde la oferta como desde la demanda), saltaron a la palestra nuevos agentes especializados en la intermediación: los consignatarios y comisionistas. Se adaptaron a las nuevas condiciones pautadas por esa coyuntura expansiva, en un ambiente económico en plena modernización, tanto en su infraestructura de transportes como en su estructura financiera. Y, lo que es más importante, mostraron una gran versatilidad, ya que se especializaron en el acopio y comercialización de harinas, azúcares u otros frutos del país, dinamizando claramente los corredores mercantiles. Además, el estudio de la temática, a través de la reducción de la escala de observación, permitió visibilizar una amplia gama de actores medianos y pequeños que participaron en la distribución de las harinas, ya sea casas comerciales o almaceneros de Tucumán y de las provincias aledañas.

En segundo lugar, ofrece pistas para entender cómo fue concretándose el proceso de integración mercantil en la Argentina de fines de siglo xIx. Si bien la bibliografía ha tendido a ubicar sus razones en el crecimiento del parque ferroviario - por cierto, algo indiscutible-, restan analizar cuestiones básicas, pero, a la vez, centrales de dicho proceso. Esto es, cuándo comenzó a integrarse, sobre qué bases se estructuró y a qué plazas conectó. En relación con estas preguntas nodales este trabajo resulta, en parte, limitado. Pero permite componer un panorama del proceso de integración en dos plazas de gran importancia, ya que eran las responsables de la producción de dos alimentos centrales de la dieta: azúcar y harinas. La evidencia presentada sugiere una complementación entre los comerciantes de ambas plazas, lo que estaría indicando no sólo la emergencia de nuevos actores, sino también la dinamización de los mecanismos de intermediación que alentó el flujo de mercancías y alimentos.

El tercer y último punto que trata el trabajo es también actualmente tópico de gran interés: la rotulación de los productos de consumo. En un mercado cada vez más complejo, el análisis de las estrategias de diferenciación del valor agregado en los alimentos ofrece nuevas herramientas para la comprensión de ese proceso de crecimiento. En el caso analizado, más allá de no presentar suficientes pruebas empíricas como para ofrecer hipótesis sobre la emergencia de las primeras estrategias de marcas o branding en el mercado de alimentos argentino decimonónico, podemos al menos arriesgar que, para la plazas norteñas, a la par del proceso de convergencia de mercados que se consolidaba en la década de 1890, se evidencian preocupaciones claras por establecer ante la clientela los productos como distintos, únicos, mejores (resaltando su calidad frente a los símiles y/o imitaciones), y lo que no es un dato menor, registrar marcas de los productos. Es de por sí una hipótesis tan arriesgada como atractiva, que sin duda profundizaremos en trabajos futuros. 
En suma, el trabajo ofrece tres proposiciones que, sabemos, necesitarán ponerse a prueba con trabajos específicos. La primera es la importancia de los intermediarios como nuevos actores como un subproducto de la modernización económica argentina de fines del siglo XIX- que se volvieron centrales para mover el engranaje de los circuitos mercantiles de las modernas industrias procesadoras de alimentos. La segunda retrograda algunos años el uso (aunque sea de manera no convencional) de las marcas de productos alimenticios básicos y, por último, la posibilidad de ubicar convergencias de mercados regionales ya en la década de 1890 .

\section{REFERENCIAS}

Adelman, J. (1990). Agricultural Credit in the Province of Buenos Aires, Argentina, 1890-1914. Journal of Latin American Studies, 22(1-2), 69. Dor: 10.1017/S0022216X0001511X

Álvarez, J. (1929). Temas de historia económica argentina. Buenos Aires: El Ateneo.

Arcondo, A. (1994). La noción de mercado en la economía y su utilización en la historia. En J. Grosso y J. Silva (eds.), Mercados e historia (pp. 19-43). México: Instituto Mora.

Barsky, O. y Gelman, J. (2001). Historia del agro argentino. Desde la conquista hasta fines del siglo XX. Argentina: Grijalbo-Mondadori.

Belini, C. (2017). Historia de la industria en la Argentina. De la independencia a la crisis de 2001. Buenos Aires: Sudamericana.

Berg, M. (ed.) (1995). Mercados y manufacturas en Europa. Barcelona: Crítica.

CAMPI, D. y Bravo, M. (1999). La agroindustria azucarera argentina. Resumen historiográfico y fuentes. América Latina en la Historia Económica, 11, 73-93. Dor: 10.18232/alhe.v6i11.240

Casson, M. (1998). Institutional economics and business history: A way forward? En M. CAsson y M. B. Rose (eds.), Institutions and the evolution of modern business (pp. 151-171). Londres: Frank Cass.

Chavanne, J. (1889). Mapa de los ferrocarriles, telégrafos y correos de la República Argentina. Cía. Buenos Aires: Sudamericana de Billetes de Banco.

Converso, F. (2001). Un mercado en expansión: Córdoba 1870-1914. Córdoba: Centro de Estudios Históricos Profesor Carlos S. A. Segreti.

Cosimano, T. (1996). Intermediation. Economica, 63, 131-143.

Dirección General de Estadística Argentina (1896). Anuario correspondiente al año 1895. Buenos Aires: Sudamericana de Billetes de Banco.

DJenderedjan, J., BeARZotti, S. y MartiréN, J. (2010). Expansión agrícola y colonización en la segunda mitad del siglo XIX. Buenos Aires: Teseo.

FERnÁndez, A. (2001). La Argentina, żun "mercado étnico"? Las exportaciones españolas en el mercado nacional (1880-1935). Barcelona: Universitat de Barcelona.

FERnÁndez, A. y Lluch, A. (2008). Comercio y redes de comercialización mayoristas y minoristas en la Argentina de comienzos del siglo xx. En M. Blanco, G. Blanco y S. Bandieri (eds.), Las escalas de la historia comparada. 2: Empresas y empresarios. La cuestión regional (pp. 57-88). Buenos Aires: Miño y Dávila.

FERnández, S. (1999). Burgueses y empresarios. La ciudad de Rosario y el espacio rural en el cambio de siglo, 1880-1914 (Tesis de maestría). Facultad Latinoamericana de Ciencias Sociales, Buenos Aires.

Fuiess, A. (1892). La producción agrícola y ganadera en la República Argentina en el año 1891. Estudio Económico-Estadístico. Buenos Aires: Imprenta de La Nación. 
FRID, C. (2006). Encontrando la clientela comerciantes e inmigrantes en el sur de Santa Fe a fines del siglo xix. En A. Bernasconi, C. Frid y F. Devoto (eds.), De Europa a las Américas: dirigentes y liderazgos (1880-1960) (pp. 149-174). Buenos Aires: CEMLA/Editorial Biblos/CEHIPE.

Gallo, E. (1983). La pampa gringa. Buenos Aires: Sudamericana.

Gallo, E. y Cortés-Conde, R. (1972). La República conservadora. Buenos Aires: Paidós.

Grosso, J. y Silva, J. (eds.) (1994). La noción de mercado en la economía y su utilización en la historia. México: Instituto Mora.

Guy, D. (1981). Política Azucarera Argentina. Tucumán y la generación del 80. Tucumán: Fundación Banco Comercial del Norte.

Hora, R. (2010). Historia económica de la Argentina en el siglo XIX. Buenos Aires: Siglo XXI Editores/Fundación OSDE.

Jones, G. (2003). Merchants to Multinationals. Oxford University Press. DoI: 10.1093/0199249997. 001.0001

Lahitte, E. y Correa, A. (1898). Investigación Parlamentaria sobre Agricultura, Ganadería, Industrias Derivadas y Colonización, Anexo G. Tucumán y Santiago del Estero. Buenos Aires: Taller Tipográfico de la Penitenciaría Nacional.

Lluch, A. (2004). Comercio y crédito en La Pampa a inicios del siglo Xx. Un estudio sobre el papel económico de los almacenes de ramos generales (Tesis doctoral). Universidad Nacional del Centro de la Provincia de Buenos Aires, Tandil.

Lluch, A. (2013). Marca registrada. Reflexiones sobre el uso de las marcas comerciales, el consumo y la comercialización de bienes en el mundo rural argentino (1900-1930). Mundo Agrario, 13(26), 1-18.

Lluch, A. (ed.) (2015). Palabras introductorias. Comercialización de bienes en perspectiva histórica: temas y contribuciones. En Las manos del mercado. intermediarios y consumidores en la Argentina (pp. 13-22). Rosario: Prohistoria.

Lopes, T. D. S. y Duguid, P. (eds.) (2010). Trademarks, brands, and competitiveness. Londres: Routledge.

MartiRén, J. (2015). Del molino a las plazas de consumo. Las cadenas de comercialización de harinas durante la segunda mitad del siglo XIX en la provincia de Santa Fe. En A. Lluch (ed.), Las manos del mercado. intermediarios y consumidores en la Argentina (pp. 23-46). Rosario: Prohistoria.

MARTIRÉN, J. L. (2016). La transformación farmer: colonización agrícola y crecimiento económico en la provincia de Santa Fe durante la segunda mitad del siglo XIX. Buenos Aires: Prometeo Libros.

Míguez, E. (2008). Historia económica de la Argentina. De la conquista a la crisis del 1930. Buenos Aires: Sudamericana.

Moore, K. y ReID, S. (2008). The birth of brand: 4000 years of branding. Business History, 50(4), 419-432. DOI: $10.1080 / 00076790802106299$

Moyano, D. (2012). Las formas del dulce. Producción, mercados y tipos de azúcares en la agroindustria tucumana (1870-1914). Revista de Historia Americana y Argentina, 47(2), 1-35.

Moyano, D. (2015). Construyendo el mercado para el azúcar argentino Un análisis sobre los intermediarios y los canales de comercialización (1885-1905). En A. Lluch (ed.), Las manos del mercado. intermediarios y consumidores en la Argentina (pp. 47-67). Rosario: Prohistoria.

Pollard, S. (1991). La conquista pacifica: la industrialización de Europa, 1760-1970. Zaragoza: Prensas Universitarias de Zaragoza. 
Provincia de Tugumán (1884). Registro estadístico de la provincia de Tucumán correspondiente al año 1882 publicado bajo la dirección del jefe de la Oficina de Estadística General de la misma Provincia, D. César Mur. Buenos Aires: Imprenta de Pablo E. Coni.

República Argentina (1876). Discurso del presidente de la república en la inauguración del Ferro-Carril Central del Norte el día 31 de octubre de 1876. Tucumán: Imprenta de la Tribuna.

República Argentina (1899). Censo Nacional 1895, levantado el 10 de mayo de 1895. Buenos Aires: Taller Tipográfico de la Penitenciaría Nacional.

República Argentina (1917). Tercer censo nacional, levantado el 1 de junio de 1914. T. viI: Censo de las Industrias. Buenos Aires: Taller Tipográfico de la Penitenciaría Nacional.

Rocchi, F. (1998). Consumir es un placer: La industria y la expansión de la demanda en Buenos Aires a la vuelta del siglo pasado. Desarrollo Económico, 37(148), 533. DoI: $10.2307 / 3467411$

Rocchi, F. (2006). Chimneys in the desert: Argentina during the export boom years, 1870-1930. Palo Alto: Stanford University Press. Recuperado a partir de http://public.eblib.com/choice/ publicfullrecord.aspx?p=3037528

Rocchi, F. (2016). Una sola Argentina. La formación de un mercado nacional de bienes industriales (1870s-1930). Presentado en XXV Jornadas de Historia Económica, Salta: Asociación Argentina de Historia Económica/Universidad Nacional de Salta.

Rodríguez-Marquina, P. (1889). Memoria descriptiva de Tucumán. La industria azucarera, su presente, pasado y porvenir. Progresos de la provincia debidos al desarrollo de la industria azucarera. Estadística. Tucumán: Autor.

SÁnchez-Román, J. A. (2005). La dulce crisis: estado, empresarios e industria azucarera en Tucumán, Argentina (1853-1914). Sevilla: Universidad de Sevilla.

Scobie, J. R. (1968). Revolución en las pampas. Una historia social del trigo en Argentina. Buenos Aires: Solar Hacette.

SERENI, E. (1980). Capitalismo y mercado nacional. Barcelona: Crítica.

Valdemarca, L. B. (2003). Comerciantes contra mercados, elites mercantiles en la Córdoba moderna. Córdoba: Universitas.

Zalduendo, E. (1975). Libras y rieles. Buenos Aires: El Coloquio.

Zeballos, E. (1894). La concurrencia universal y la agricultura en ambas Américas. Washington: Gibson Bros.

Archivos

AgN Archivo General de la Nación, Buenos Aires, Argentina

AHH Archivo del Museo Histórico de Humboldt, Humboldt, provincia de Santa Fe, Argentina.

AMce Archivo del Museo de la Colonización de Esperanza, Esperanza, provincia de Santa Fe, Argentina. 